\title{
Management of sickle cell disease
}

\author{
Milica Brozović and Sally Davies
}

Department of Haematology, Central Middlesex Hospital, Acton Lane, London, NW10, UK.

Sickle cell disease (SCD) is one of the commonest inherited diseases in Britain with an estimated number of between 4000 and 5000 sufferers. ${ }^{1,2}$ About 1 in 200 babies born to West Indians and 1 in 100 born to Africans have SCD and at least 150 babies with SCD are born in Britain every year. General practitioners and hospital doctors will therefore be increasingly involved in the care of both children and adults with SCD and so need to know about the many aspects of this disease.

Children with SCD are usually cared for by a paediatrician with a special interest in haemoglobinopathies, or a paediatric haematologist, and transferred to the care of a haematologist in adolescence. Assistance from other clinical specialists including orthopaedic surgeons, urologists and neurologists, as well as of nurses, counsellors and social workers in a large specialist centre appears to offer the best chance of a long survival without serious complications. This requires good communication and cooperation between the specialist centre and the non-specialist, particularly if the centre is not local.

\section{Genetics and pathophysiology}

SCD is a term which covers many different inherited abnormalities of haemoglobin that are all characterized by the sickling phenomenon: that is the alteration of the normal discoid elastic red blood cell into a rigid 'sickled' cell. When haemoglobin S (HbS) becomes deoxygenated it polymerizes into long crystals, 'tactoids', which distort the shape of the cell making it rigid and sickled, ${ }^{3}$ when the $\mathrm{PO}_{2}$ is over $35 \mathrm{~mm} \mathrm{Hg}$, sickling only takes place in the red cells of those individuals who have inherited $\mathrm{HbS}$ from both parents, or who have inherited $\mathrm{HbS}$ from one parent and another haemoglobin abnormality from the other parent. The four main genotypes of SCD in Britain are shown in Table I.

All the manifestations of SCD can be explained by three main underlying mechanisms: vaso-occlusion, haemolytic anaemia and a propensity to infections. Vaso-occlusion, which can occur anywhere in the body (but most frequently in the bones) is caused by the blockage of blood vessels by sickled red cells.

Table I Main genotypes of sickle cell disease in Britain

\begin{tabular}{|c|c|c|c|}
\hline Genotype & $\begin{array}{c}\text { Abbrevia- } \\
\text { ted } \\
\text { name }\end{array}$ & $\begin{array}{c}\% \text { of } \\
\text { cases } \\
\text { in Britain }\end{array}$ & Comment \\
\hline $\begin{array}{l}\mathrm{HbS} / \mathrm{HbS} \\
\text { (sickle cell anaemia) }\end{array}$ & SS & 50 & $\begin{array}{l}\text { Severe anaemia, frequent painful } \\
\text { crises. }\end{array}$ \\
\hline $\begin{array}{l}\mathrm{HbS} / \mathrm{HbC} \\
\text { (SC disease) }\end{array}$ & SC & 40 & $\begin{array}{l}\text { Mild anaemia or no anaemia. Eye } \\
\text { and bone disease. }\end{array}$ \\
\hline $\begin{array}{l}\mathrm{HbS} / \boldsymbol{\beta}^{\circ} \text { thalassaemia trait } \\
\left(\mathbf{S} \beta^{\circ} \text { thalassaemia) }\right.\end{array}$ & $\mathbf{S} \boldsymbol{\beta}^{\circ}$ & 3 & $\begin{array}{l}\text { Severe anaemia, frequent painful } \\
\text { crises. }\end{array}$ \\
\hline $\begin{array}{l}\mathrm{HbS} / \beta^{+} \text {thalassaemia trait } \\
\left(\mathbf{S} \beta^{+} \text {thalassaemia) }\right.\end{array}$ & $\mathbf{S} \boldsymbol{\beta}^{+}$ & 6 & Mild anaemia. Eye and bone disease. \\
\hline $\begin{array}{l}\mathrm{HbS} / \mathrm{HbD}, \mathrm{HbS} / \mathrm{HbO} \\
\mathrm{Hb} / \mathrm{SHbE}, \mathrm{HbS} / \mathrm{HbY}\end{array}$ & $\begin{array}{l}\text { SD,SO } \\
\text { ST,SY }\end{array}$ & 1 & Variable \\
\hline
\end{tabular}

Correspondence: M. Brozović, F.R.C.Path

Received: 15 January 1987 
Subsequent ischaemia and later necrosis provoke severe pain and systemic disturbance known as the painful crisis. Sickled red cells have a shorter than normal life span resulting in a haemolytic anaemia which is severe in patients with sickle cell anaemia (SS) and relatively mild in those with sickle cell $\mathrm{HbC}$ disease (SC). From an early age patients with SCD have hypofunctional spleens as well as complex abnormalities of the immune system. These give rise to a propensity to severe bacterial infections, in particular those caused by Streptococcus pneumoniae and Salmonella species.

About $10 \%$ of West Indians, $15-20 \%$ of Africans, and a smaller percentage of Indians, Arabs, and Mediterraneans carry the sickle gene. ${ }^{4}$ Carriers of $\mathrm{HbS}$ are completely healthy. A test for carrier detection (haemoglobin electrophoresis) can be performed in most if not all British hospitals. Antenatal diagnosis using DNA technology on fetal material (chorionic villi, amniotic fluid cells or fetal blood) is now widely available.

\section{Diagnosis of sickle cell disease}

Affected babies can be diagnosed at birth by haemoglobin electrophoresis of blood samples obtained from the umbilical cord or heel prick. ${ }^{5,6}$ The diagnosis should always be confirmed at 6 weeks of age. In older children and adults, once suspected, the diagnosis is easily established with a combination of laboratory tests (haemoglobin electrophoresis, solubility test and blood count).

\section{Main problems in infancy and early childhood}

In Jamaica up to $18 \%$ of children with SCD die during the first five years of life from pneumococcal septicaemia and from acute splenic sequestration. ${ }^{7}$ Acute splenic sequestration often occurs in association with infection; the child's spleen enlarges suddenly due to trapping of the red cells, resulting in a rapid fall in haemoglobin, collapse, shock and death. Children with SCD also have functional asplenia and impaired immunity from an early age; this predisposes them to overwhelming pneumococcal infections. The highest risk of death is during the second 6 months of life but serious infections may occur earlier, from about 4 months of age. Cot deaths are often mistakenly diagnosed in these cases. Much of the early morbidity and mortality is prevented by oral penicillin prophylaxis. ${ }^{8}$ This provides a cogent argument for the diagnosis of SCD at birth; penicillin prophylaxis should be started as soon as the diagnosis is confirmed ( 6 weeks of age), the parents educated about potential problems, and the general practitioner made aware of the child and his disease.

In children not receiving penicillin prophylaxis pneumococcal infections are frequently fulminant and may be associated with acute splenic sequestration, Waterhaus-Friderichsen's syndrome, stroke and a rapid death. ${ }^{8}$ Other serious infections such as Haemophilus influenzae meningitis may also occur.

The hand-foot syndrome is also common during the first 3 years of life and is due to occlusion of blood vessels in the metatarsal and metacarpal bones. The infant's hands and feet become swollen, hot and tender with an associated soft tissue reaction and the child is usually pyrexial.

\section{Main problems in late childhood, adolescence and adulthood}

As the child grows older the incidence of painful crises increases. Vaso-occlusion initially occurs in the long bones but as adolescence approaches the pain tends to shift centrally, to the spine, pelvis, chest and abdomen. The pain can be excruciating and associated fever and tachycardia are common. The treatment of the painful crisis is at present only symptomatic: pain relief, hydration and prophylactic antibiotics. Adequate pain relief is essential and if the pain does not respond to simple analgesia (paracetamol, codeine), the patiens should be referred to hospital for adequate controk. The importance of hydration cannot be overeno phasized because patients with SCD have hyposthenuria from an early age. This renal concentration defect leads to a rapid and severe dehydration in the presence of pyrexia or vomiting. ${ }^{9}$ The consequent reduction in plasma volume increases the tendency to sickle and further aggravates the crisis. Children and adults who are unable to drink at least $60 \mathrm{ml}$ of fluid per $\mathrm{kg}$ of body weight per 24 hours should be referred to hospital for intravenous administration of fluids. Antibiotics are given to prevent secondary infection of the ischaemic tissues in the already immunocompromised patient.

\section{Visceral sequestration crises}

Sequestration of sickled red cells in the viscera is a life threatening situation. Splenic sequestration usually occurs in small children, often in association with severe infections. In older children, the spleen becomes atrophic from repeated episodes of sickling, and sequestration may occur in the liver resulting in severe abdominal pain, rapid enlargement of the liver and a fall in haemoglobin concentration. ${ }^{10}$ Sequestration also occurs in the lungs, the 'chest syndrome', an acute illness with pneumonic consolidation. The patient is breathless and has chest and/or back pain. Cough is not generally a prominent feature. Consolidation 
quickly develops in the bases, rising to the middle zones of the lungs and is often bilateral. The chest Xray may remain normal in the early stages despite marked physical signs. The most severe sequestration syndrome of adults with the highest mortality, the 'girdle syndrome', involves the lungs, liver and mesenteric circulation simultaneously. The patient is very ill, breathless, in severe pain, with bilateral chest signs and a silent, distended but often soft abdomen, and an enlarged liver. This is a medical emergency and any patient with suspected visceral sequestration must be sent to hospital without delay. Many will only respond to rapid exchange transfusion (see below) which is indicated when there is a sudden drop in haemoglobin concentration to below $5 \mathrm{~g} / \mathrm{dl}$, the arterial $\mathrm{PO}_{2}$ on air falls to below $60 \mathrm{~mm} \mathrm{Hg}$ or bowel sounds remain absent for over 3 days in a clinically deteriorating patient.

\section{Joints}

Swollen, hot and tender large joints with obvious effusions are usually due to sickling and infarction in the juxta-articular region. In the presence of high fever a septic arthritis may be suspected, but is a rare complication of SCD in Britain. Such joints should never be aspirated as a first line diagnostic approach because the incidence of secondary infection and joint damage is high.

\section{Bones}

Aseptic necrosis of hips and shoulders is found in over $10 \%$ of patients and even occurs in early childhood. ${ }^{12}$ When the pain and limitation of movement become severe, joint replacement is required. The patient must receive exchange transfusion both pre- and postoperatively to allow for optimum bone healing. These operations are best undertaken by an orthopaedic team with experience in SCD.

\section{Stroke}

Some $7 \%$ of children with SS develop an acute hemiplegia. The earliest age of onset described is 2 years, but the median age in the USA is 7 years. ${ }^{13}$ There is a high recurrence rate during the first 3 years following the episode. The child with an acute stroke must be referred to a specialist centre with utmost urgency for immediate exchange transfusion. Once fully exchanged ( $\mathrm{HbS}$ less than $20 \%$ ) the patient requires assessment, e.g., by angiography, to establish how many and which blood vessels are occluded. If more than one vessel is involved the child is hypertransfused (see below) for 3 years. Most children make an excellent recovery if immediately exchange transfused and kept on regular transfusion for a period of 3 years. A small number may develop another stroke when transfusion is stopped and such children may have to remain on blood transfusion for life.

\section{Priapism}

Up to $50 \%$ of men with SCD may develop either multiple attacks of painful erections (stuttering priapism) or a major attack. ${ }^{14}$ Patients with stuttering priapism should be referred to a specialist centre. Stuttering priapism may herald a major attack and it is probably advisable to start such patients on cyproterone, initially at low dose (50 $\mathrm{mg}$ twice daily). A patient with a major attack must be sent to hospital immediately because exchange transfusion is often successful in resolving the attack if given within 24 hours of the onset. After 24 hours, surgical intervention is usually unavoidable; the results are disappointing and up to half of the patients are subsequently impotent although erectile function may continue to improve for up to 2 years.

\section{Infections}

Patients should continue on prophylactic penicillin up to the age of 16. Pneumovax should ideally be given before penicillin is discontinued. In unvaccinated adults pneumococcal pneumonia and meningitis remain a serious problem. Salmonella septicaemia and osteomyelitis are frequent in patients with SCD. If suspected the patient should be referred to hospital for blood cultures, biopsies, bone scans and intravenous antibiotic treatment. Osteomyelitis may also be caused by Escherichia coli and Staphylococcus aureus. Urinary tract infections are also frequent in patients with SCD and should always be treated energetically because they may lead to septicaemia, osteomyelitis and serious chronic kidney problems.

\section{Aplastic crisis}

This is always due to infection, most commonly with parvovirus. ${ }^{15}$ In healthy children parvovirus can cause an exanthematous rash with a mild febrile illness whereas in children with a chronic haemolytic anaemia such as SCD it causes arrest of erythropoiesis with a sudden drop in haemoglobin to values as low as $1-2 \mathrm{~g} / \mathrm{dl}$. Blood transfusion is almost always needed. The disease occurs in epidemics, often in siblings and school friends. It is always self-limiting.

\section{Other problems}

Most patients with SCD are clinically jaundiced not only in the crisis but also in the steady state as a result of chronic haemolytic anaemia. Pigment gallstones are therefore common and may precipitate severe 
abdominal vaso-occlusive crises. Once a patient has had a major vasoocclusive episode associated with gallbladder disease or a severe cholecystitis, cholecystectomy should be performed.

Heart Patients with SS and $\mathrm{S} \beta^{\circ}$ have large hearts and often loud functional murmurs as a result of their anaemia. Many are unnecessarily investigated for congenital heart abnormalities.

Splenomegaly One in ten patients with SS and $\mathbf{S} \boldsymbol{\beta}^{\circ}$, and one in three with $\mathrm{SC}$ and $\mathrm{S}^{+}$have splenomegaly. Splenectomy should be considered if there is evidence of hypersplenism or if the patient experiences recurrent painful splenic infarcts.

Eye complications are common. In Jamaica $36 \%$ of all the patients with SC and $12 \%$ of those with SS have evidence of a proliferative retinopathy. ${ }^{16}$ The condition usually starts in adolescence, so all young patients with SCD should have regular ophthalmological review. Treatment is aimed at reducing the risk of vitreous haemorrhage and retinal detachment through photo- or laser coagulation of the lesions.

Renal problems include urinary tract infections, papillary necrosis (usually presenting as haematuria), nephrotic syndrome and chronic renal failure. All these problems are more common in adults than in children. In children enuresis is often troublesome because of the large obligatory fluid loss. Fluid restriction is contraindicated because it only aggravates the underlying renal pathology.

\section{Growth and puberty}

Children with SCD, in particular those with SS are almost invariably thin and many, especially the boys, experience delayed puberty. The majority do enter puberty by the age of 18 and only a small number require specialist endocrinological expertise.

\section{Oral contraception}

The thrombotic risks associated with the oestrogencontaining contraceptive pill must always be discussed with the patient. The progesterone-only pill, intrauterine devices, chemical and barrier contraceptive measures should be offered as the first choice and only if the woman finds all these alternatives unacceptable and understands the risks involved, may the low oestrogen pill be prescribed. The risks associated with an unwanted pregnancy far outweigh those of the oestrogen-containing pill.

\section{Fertility and pregnancy}

Many men with SS have low sperm counts and are

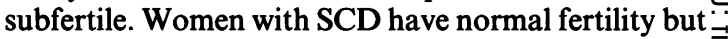
pregnancy is associated with an increased frequency of painful crises and the chest syndrome and a more rapido progression of retinopathy and bony aseptic necrosis. There is a high incidence of miscarriages and stillbirths $\overline{\overline{\underline{\rho}}}$. with many of the babies being small for dates. All $\mathbb{D}$ pregnant women with SCD should be referred to an obstetric unit with experience in managing women ${ }^{\text {s }}$ with SCD. Some women with SS may need regular $\overrightarrow{0}$ transfusion throughout pregnancy.

\section{Surgery and anaesthesia}

Most surgical procedures can be carried out without exchange transfusion provided the patient is given $\omega$ fluids (3.5 litres $/ \mathrm{m}^{2}$ body surface/24 hours, intravenously) starting when the oral intake is stopped, careful oxygenation throughout the operation and recovery, of prophylactic antibiotics, vigorous chest physioth-o erapy, and subcutaneous heparin $(5,000$ IU twice daily) if the platelet count is over $400 \times 10^{9} / 1$ and when the patient is to be immobile for over $24 \mathrm{~h}$ as afterco cholecystectomy or hip replacement. There are however, some procedures which are not safe without an exchange transfusion: surgery for retinal detac $-\infty$ ment, hip or shoulder joint replacement, all neurosur. gical procedures, and major abdominal or thoracis surgery. It is important to assess every patient individually and to discuss the pre- and perioperative measures with the specialist centre.

\section{Blood transfusion}

Patients with SS generally have haemoglobin of 6 $10 \mathrm{~g} / \mathrm{dl}$ in the steady state, which usually falls by $1 \mathrm{~g} / \mathrm{dl}$ or more during the crisis. Patients do not require transfusion for the correction of anaemia unless their haemoglobin is below $5 \mathrm{~g} / \mathrm{dl}$, because $\mathrm{HbS}$ has a lowoxygen affinity and achieves good tissue oxygenation 3 . despite the anaemia.

Simple blood transfusion is used only in emergencies if there is a sudden drop in haemoglobin as in aplastic crisis, sequestration crisis, or acute haemorrhage. In all other situations the patient must be simultaneously venesected and given blood ('exchange transfused'). This is done in order to minimize the risk $\stackrel{N}{\circ}$ of sludging and vaso-occlusion associated with rise in $N$ blood viscosity and caused by giving donor blood with high packed cell volume. The aim of an 'exchange $\omega$ transfusion' is to reduce the percentage of $\mathrm{HbS}$ to below $20 \%$; this is usually achieved by exchanging two and a half blood volumes (at least 15 units of blood for $\stackrel{D}{\Phi}$ an average adult with $S C D$ ).

Some patients with stroke or renal failure need $\frac{0}{0}$ 
hypertransfusion, that is, regular transfusions to completely, or almost completely, prevent production of $\mathrm{HbS}$ by the marrow for long periods of time. These patients, with time, will develop iron overload and should therefore be treated with iron chelators, e.g., desferrioxamine, in the standard manner.

\section{Mortality}

The exact figure for mortality is not known in Britain, but is likely to be similar to that in the $\mathrm{USA}^{17}$ and Jamaica: ${ }^{18}$ over $10 \%$ of children die during the first decade of life from severe infections and acute splenic sequestration. Thereafter, the mortality is approximately $5 \%$ per decade of life. The main causes of death are chest and girdle syndromes, cerebrovascular accidents and infections.

\section{Psychological and social problems}

At the time of diagnosis the parents need expert counselling about the implications of the disease for their child. This is best done by trained haemoglobinopathy counsellors through one of the sickle cell centres.

1. Prashar, U., Anionwu, E. \& Brozović, M. Sickle Cell Disease. Who Cares? The Runnymede Trust 1985.

2. Brozović, M. \& Anionwu, E. Sickle cell disease in Britain. J Clin Path 1984, 37: 1321-1326.

3. Dean, J. \& Schlecter, A.N. Sickle cell anemia: molecular and cellular basis of therapeutic approaches. $N$ Engl $J$ Med 1978, 299: 752-763.

4. Serjeant, G.R. In Sickle Cell Disease. Oxford University Press, Oxford, 1985, pp 19-24.

5. Henthorn, J., Anionwu, E. \& Brozović, M. Screening cord blood for sickle haemoglobinopathies in Brent. $\mathrm{Br}$ Med J 1984, 289: 479-480.

6. Horn, M.E.C., Dick, M.C., Frost, B. et al. Neonatal screening for sickle cell disease in Camberwell; results and recommendations of a two year pilot study. $\mathrm{Br} \mathrm{Med}$ $J$ 1986, 292: 737-740.

7. Rogers, D.W., Clarke, J.M., Cupidore, L. et al. Early deaths in Jamaican children with sickle cell disease. $\mathrm{Br}$ Med J 1978, 278: 1515-1516.

8. Gaston, M.H., Verter, J.L., Woods, G. et al. Prophylaxis with oral penicillin in children with sickle cell anemia. $N$ Engl J Med 1986, 314: 1593-1599.
Recurrent episodes of painful illness, enuresis, failure to grow, and delayed puberty can cause severe psychological problems. Children with SCD should, where possible, attend normal schools and be encouraged to achieve their full academic notential as heavy manual jobs are unsuitable. All need a sympathetic school and many require extra tuition. Expert advice from the sickle cell centre on careers, disability, various allowances and other problems is helpful. Selfhelp groups and the two national charities, the Sickle Cell Society and Organisation for Sickle Cell Anaemia Research (OSCAR), play an important role in informing and educating patients, parents and health professionals.

\section{Conclusions}

Sickle cell disease is common in urban districts of Britain and the number of patients is increasing. Many are likely to achieve a normal or nearly normal life span. The management of sufferers is complex and requires the experience of different specialists. Patients should be referred to a specialist centre for supervision of their management annually or biannually. The nonspecialist should become increasingly involved in the management of SCD and in the prevention of its common complications.

9. Serjeant, G.R. In Sickle Cell Disease. Oxford University Press, Oxford, 1985, pp 213-217.

10. Hatton, C.S.R., Bunch, C. \& Weatherall, D.J. Hepatic sequestration in sickle cell anaemia. $\mathrm{Br} \mathrm{Med} J \mathrm{~J}$ 1985, 290: 744.

11. Davies, S.C., Win, A.A., Luce, P.J. et al. Acute chest syndrome in sickle cell disease. Lancet 1984, i: 36-38.

12. Serjeant, G.R. In Sickle Cell Disease. Oxford University Press, Oxford, 1985, pp 184-191.

13. Powars, D.R., Wilson, B., Imbus, C. et al. The natural history of stroke in sickle cell disease. Am J Med 1978, 65: 461-472.

14. Emond, A.M., Holman, R., Hayes, R.S. \& Serjeant, G.R. Priapism and impotence in sickle cell disease. Arch Int Med 1980, 140: 1434-1438.

15. Serjeant, G.R. In Sickle Cell Disease. Oxford University Press, Oxford 1985, pp 72-77.

16. Serjeant, G.R. In Sickle Cell Disease. Oxford University Press, Oxford 1985, pp 247-250. 